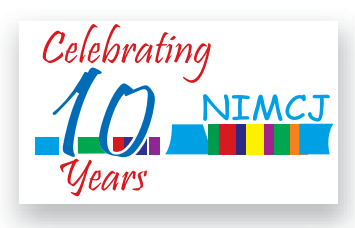

${ }^{1}$ Dr. Nasreen Sultana

Junior consultant (Gynae \&Obs)

50 bedded hospital

Rupganj, Narayanganj

${ }^{2}$ Dr. Shamima Rahman

Junior consultant (Gynae \& Obs)

${ }^{3}$ Dr. Fakhruddin Ahmed

Junior consultant (Anesth)

${ }^{4}$ Dr. SK. Ashraf Ullah

Associate Professor (c.c)(Orth.)

Northern International Medical

College, Dhaka

2,3

50 bedded hospital

Rupganj, Narayanganj

\section{Correspondence}

Dr. Nasreen Sultana

Junior consultant (Gynae \& Obs)

50 bedded hospital

Rupganj, Narayanganj

e-mail: nasreensultana600915@gmail.com

\title{
Alpha Feto Protein in vaginal fluid as a diagnostic marker of Premature rupture of membrane
}

\author{
N Sultana ${ }^{1}$, S Rahman², F Ahmed ${ }^{3}$, SK A Ullah ${ }^{4}$
}

Abstract

Background : Premature Rupture of Membrane (PROM) is a significant obstetric emergency where a normal pregnancy suddenly becomes a high risk one. It can cause serious complications of mother and fetus. Patient's history, per speculum vaginal with Nitrazine paper test and Fern test considered as gold standard for diagnosis of PROM. But these multiple tests are hazardous and time consuming. Therefore Alpha-Feto Protein (AFP) test is a single sensitive test for proper diagnosis of PROM.

Objective : To evaluate the accuracy of Alpha-Feto protein in vaginal fluid as a diagnostic tool of PROM.

Method : It was a cross sectional study, carried out among 120 pregnant women who had the gestational age between 28th to 40th week of pregnancy. Sample was collected purposively and divided into two groups. In group-I-62 suspected PROM patients were selected who gave the history of per vaginal watery discharge and was found positive in per speculum examination (P/S). In group-II-58 non PROM pregnant patients were selected. Then in group-I, Nitrazine paper test and Fern test were done to confirme PROM patients. Both groups AFP test was done by AxSYM auto analyzer. Finally the accuracy of AFP was evaluated against the gold standard test.

Result : It was found that AFP concentration was significantly higher in group-I of suspected PROM patients (30. $502 \mathrm{ng} / \mathrm{ml})$ than in group $-I I(0-40 \mathrm{ng} / \mathrm{ml})$. Among 62 suspected PROM patients 49 were found gold standard (Nitrogen paper test and Fern test) positive. Out of these 49 confirmed PROM patients 48 was found positive in Alpha-Feto protein test. The sensitivity of AFP test was found $98 \%$, specificity was $84.6 \%$ and accuracy was $95.1 \%$.

Conclusion : As Alpha-Feto protein in vaginal fluid was found highly accurate $(95.1 \%)$ for diagnosis of PROM. Therefore, AFP test can be used as a single sensitive test for diagnosis of PROM.

DOI: $10.3329 /$ nimcj.v10i1.39327

Northern International Medical College Journal Vol. 10 No. 1 July 2018, Page 335-338

\section{Introduction}

During pregnancy every fetus remains within uterus inside the amniotic sac made up of membranes and floats on amniotic fluid ${ }^{1}$. Under normal circumstances these membranes rupture spontaneously during active phase of labour ${ }^{2}$. But when membranes rupture before the initiation of labour it is considered as premature rupture of membrane (PROM) ${ }^{3}$.

PROM is a high risk case and a serious obstetrical emergency both for mother and fetus. Most disastrous complication of PROM is preterm labour, delivery of a premature low birth weight baby, cord prolapsed, ARDS, fetal pneumonia etc. Another clinical concern of PROM is serious maternal infection like chorioamnionitis which may endanger both maternal and fetal life 4 .
In our country PROM patients are diagnosed only by traditional methods of history and per speculum examination. But these are not sufficient for diagnosis because similar findings may present in other cases like hydrorrhoea graviderum, vaginal infection and urinary incontinence ${ }^{5}$. Thus many pregnant women with intact membrane may be diagnosed falsely as PROM patients. On the other hand in many occasions, actual PROM patients who have scanty or intermittent appearance of fluid in per speculum examination may be deprive from actual diagnosis. Although Nitrazine paper test and Fern test along with history and per speculum examination altogether are 100\% specific and considered as 'gold standard' for diagnosis of PROM. But multiple tests are hazardous, difficult and needs clinical expertise. Considering the drawbacks of multiple tests it is 
very much desirable to develop a single highly specific test for proper diagnosis of PROM. Such a test is Alpha-Feto protein (AFP) test. With this test diagnosis of PROM is possible by identify AFP in vagina.

Alpha-Feto protein is a glycoprotein of fetal origin which is synthesized in fetal yolk sac, liver and gastrointestinal tract. From fetal source Alpha-Feto protein comes to amniotic fluid and present throughout the whole pregnancy ${ }^{6}$. As AFP is absent in the vaginal fluid of normal pregnant and non pregnant women and without rupture of amniotic membrane it is undetected in vaginal secretion. Therefore presences of AFP in vagina only indicate amniotic fluid after rupture of the membrane. Depending on this principle in this study the concentration of AFP was measured in vaginal fluid by Micro particle enzyme immunoassay (MEIA) technique using auto analyzer (AxSYM) immunochemistry auto analyzer to evaluate accuracy of AFP as a single sensitive test for diagnosis of PROM patients.

\section{Material and Methods}

This cross sectional study was carried out at the Department of Obstetrics and Gynecology of Sir Solimullah Medical College and Mitford Hospital, Dhaka. Among the patients attended both the inpatients and outpatients department, 120 pregnant women both primipara and multipara with the gestational age from $28^{\text {th }}$ weeks up to $40^{\text {th }}$ weeks were selected purposively for the study during the period of July 2016 to March 2018,

The study sample was divided in two groups, in group-I (suspected PROM)-62 patients who gave the history of PROM within 72 hours and found positive for per speculum examination. In group-II (pregnant patients without PROM)-58 pregnant patients had no history of PROM and found negative with per speculum examination but their gestational age were same as group-I, Then group-I patients of suspected PROM, Nitrazine paper test and Fern test (Gold standard) were performed for the confirmation of PROM patients. Alpha-Feto protein concentration was measured in both group-I and groupII patients.

A structured written questionnaire was used as research instrument for data collection. Ethical clearance was taken from the hospital authorities. Before data collection an informed and written consent was taken from the patient then questionnaire was filled up and sample (vaginal fluid) was collected. Assurance was given to the patient that such type of test will be helpful for diagnosis and management of her present pregnancy state.

Raw data after collection was organized, edited properly and analyzed by SPSS version 20. Following statistical tests were done :

1) Arithmetic Mean, 2) Standard Deviation, 3) Mann Whitney-U test, 4) Chi-Square test, 5) Sensitivity, 6) Specificity, 7) Positive predictive value, 8) Negative predictive value, 9) Accuracy.

\section{Sample collection}

For group I patient speculum examination with utmost gentleness was performed for collection of fluid that was used for Nitrazine paper test and also for Fern test. Another sterile cotton swab stick was introduced into the vagina for collection of vaginal fluid and used for AFP test. After withdrawal of the stick it was placed into a sterile test tube containing 750 microgram phosphate buffer solution (for preservation of protein portion of sample). The collected sample was then preserved at -20cc in refrigerator. This preserved sample was used for measurement of Alpha-Feto protein. For of group-II patients only vaginal fluid was collected by swab stick for measurement of concentration of Alpha-Feto Protein.

Laboratory tests (Nitrazine paper test, Fern test, Alpha-Feto Protein test) were done in the Biochemistry lab of IBN Sina D Lab and Imaging Center. Sample preservation was done in the Immunology department of BSMMU.

\section{Result}

The age distribution between the groups showed maximum study subjects of group-I (nearly 44\%) were in the range of 2630 years of age, followed by $29 \%$ between $21-25$ years and $22.6 \%$ between $31-35$ years. In group-II, age range was half (51.7\%) between $21-25$ year, followed by $27.6 \%$ between $31-35$ years and $19 \%$ between $26-30$ years.( Table -1 )

\begin{tabular}{lcc}
$\begin{array}{l}\text { Table I : Comparison of age between groups } \\
\text { Age }(\mathbf{y r s}) \#\end{array}$ & \multicolumn{1}{c}{ Group } \\
& Group-I (n=62) & Group- II ( $\mathbf{n = 5 8 )}$ \\
$<20$ & $02(3.2)$ & $01(1.7)$ \\
$21-25$ & $17(29.0)$ & $30(51.7)$ \\
$26-30$ & $27 .(43.5)$ & $11(19.0)$ \\
$31-35$ & $15(22.6)$ & $16(27.6)$ \\
$>35$ & $01(1.6)$ & 0.0 \\
Mean \pm SD & $29.15 \pm 4.36$ & $28.57 \pm 3.37$
\end{tabular}

Distribution of patients by parity showed that majority (74.2\%) of group-I was multipara compared to $44.8 \%$ of group-II, suggesting an association of PROM with multiparity $(p<0.001)$. the primiparas in group-I and group-II were $25.8 \%$ and $55.2 \%$ respectively (Table-II).

\begin{tabular}{|cccc}
$\begin{array}{c}\text { Table }- \text { II : Comparison of parity between groups }(\mathbf{n = 1 2 0}) \\
\text { Parity }\end{array}$ & \multicolumn{2}{c}{ Group } & p-value \\
& Group-I $(\mathbf{n = 6 2})$ & Group- II $(\mathbf{n = 5 8})$ & \\
Primipara & $16(25.8)$ & $32(55.2)$ & $<0.001$ \\
Multipara & $46(74.2)$ & $26(44.8)$ &
\end{tabular}

Comparison of Alpha-Feto protein in vaginal fluid between groups demonstrates that median concentration of Alpha-Feto 
protein in group-I was significantly higher $(226.0 \pm 12.8 \mathrm{ng} / \mathrm{ml})$ than that in group-II $(1.14 \pm 1.03 \mathrm{ng} / \mathrm{ml})(p<0.001)$. The alphaFetoprotein concentration in group-I was ranged between 30 $502 \mathrm{ng} / \mathrm{ml}$ and that of group-?? was between $0-40 \mathrm{ng} / \mathrm{ml}$. (Table - III)

Table-III : Comparison of Alpha-Feto protein between groups $(n=120)$

\begin{tabular}{lccc} 
Group & \multicolumn{2}{c}{ Alpha-Feto protein $(\mathrm{ng} / \mathrm{ml})$} & \\
& Median \pm SEM & Range & p-value \\
Group-I & $226.0 \pm 12.8$ & $30-502$ & $<0.001$ \\
Group-II & $01.14 \pm 1.03$ & $0=40$ &
\end{tabular}

\# Mean Whitney-U test was done to analyze the data; level of significance was 0.05 .

Results of both Nitrazine paper test and Fern test revealed that out of 62 patients of suspected PROM diagnosed by history and per speculum examination, $50(80.6 \%)$ were diagnosed as having PROM by Nitrazine paper test.12 patients were negative for the test. By Fern test 54(87.1\%) patients were diagnosed as having PROM and 8 were found negative for that test. Thus out of 62 patients, 49 were found double test positive (gold standard) and 13 were double test or single test negative. (Table - IV)

\begin{tabular}{|c|c|c|c|}
\hline \multirow[t]{2}{*}{ Diagnostic tests } & \multicolumn{2}{|c|}{ Test findings } & \multirow{2}{*}{$\begin{array}{l}\text { Total } \\
\text { e) }\end{array}$} \\
\hline & Positive & Negative (single or double) & \\
\hline Nitrazine paper test & 50 & 12 & 62 \\
\hline Fern test & 54 & 8 & 62 \\
\hline Double test (gold standard) & 49 & 13 & 62 \\
\hline
\end{tabular}

Table-V and table-VI showed the accuracy of vaginal fluid alphaFeto protein as a diagnostic test for detecting PROM in Pregnant mother. Using formulae for accuracy test it was found that sensitivity of alpha-Feto protein in vaginal fluid (at cutoff value of $30 \mathrm{ng} / \mathrm{ml}$ ) in correctly diagnosing PROM among those who had the disease was (48/49) $100=98 \%$, while the specificity of the test in correctly detecting those who did not have the disease was (11/13) $100=84.6 \%$. The positive predictive value (PPV) of the test was (48/50) $100=96 \%$ and the negative predictive value of the test was (11/12) $100=91.7 \%$. The diagnostic accuracy of the test thus derived from the formula is $(48+11) /(48+2+1+11) 100=95.1 \%$.

Table - V : Diagnostic accuracy of vaginal alpha-Feto protein to detect PROM

\begin{tabular}{lccc} 
Vaginal fluid alpha-Fetoprotein & \multicolumn{2}{c}{ PROM } & Total \\
& Positive & Negative & \\
Positive $(>30 \mathrm{ng} / \mathrm{ml})$ & 48 & 02 & 50 \\
Negative $(<30 \mathrm{ng} / \mathrm{ml})$ & 01 & 11 & 12 \\
Total & 49 & 13 & 62
\end{tabular}

Table - VI : Diagnostic accuracy of alpha-Feto protein test

$\begin{array}{lc}\text { Components of accuracy test } & \text { Percentage } \\ \text { Sensitivity } & 98 \% \\ \text { Specificity } & 84.6 \% \\ \text { Positive predictive value } & 96 \% \\ \text { Negative predictive value } & 91.7 \% \\ \text { Accuracy } & 95.1 \%\end{array}$

\section{Discussion}

In the current study the age of majority (43.5\%) of the suspected PROM patients were within the range of 26-30 years whereas the range of most of the non PROM patients (51.7\%) was $21-25$ years. The mean age of the groups was $29.15 \pm 4.36$ and $28.57 \pm 3.37$ respectively. The mean age of two groups was almost consistent. Methews and $\mathrm{Neil}^{8}$ in UK observed almost near age ranges among PROM patients. In this study, majority of the PROM patients were more than 28 years old. But Ahmed $\mathrm{N}^{9}$ found in her study that nearly half of the PROM patients were within the age range of 20-24 years. In another Bangladeshi study Akter ${ }^{10}$ found the highest frequency was from 31-35 years. All of these findings are dissimilar. The variation of age group in different studies suggests that PROM does not occur in any specific age group.

The result of the current study was found majority of the PROM patients were multipara (75\%) compared to that of primipara (44.8\%) patients and this was matched with a study of our country conducted by Parry et $\mathrm{l}^{2}(62 \%)$ with PROM.

In the current study Alpha-Feto protein concentration was measured in both group-I (suspected PROM) patients and in group-II (pregnancy without PROM) patients. The range of concentration among the PROM patients was found much higher in group I (30-502 $\mathrm{ng} / \mathrm{ml})$ than the non PROM patients of group-II it was $0-40 \mathrm{ng} / \mathrm{ml}$. This finding indicated that concentration of AFP absent or almost negligible in the normal pregnant patients with no PROM.

In this research work, the sensitivity of AFP test for correctly diagnosing PROM patients was found $98 \%$. The specificity for diagnosing those who did not have PROM was $84.6 \%$. The positive Predictive value (PPV) and negative predictive value (NPV) was $96 \%$ and $91.7 \%$ respectively. The accuracy of AlphaFeto protein for diagnosis of PROM patients was $95.1 \%$. so in this study, Alpha-Feto protein test in vaginal fluid showed quite satisfactory result in diagnosis of PROM.

Very negligible amount of patients showed false positive and false negative test result. Among the total 49 patients of confirmed PROM who were diagnosed by gold standard, one patient was negative for AFP test. This small amount of false negative due to the error in sampling or technical difficulties in running the assay and also due to the concentration of sample 
by maternal bloods or urine which impeded assay interpretation. Two patients were found positive for AFP test that were negative by gold standard. The cause of this false positive interpreted as micro stretching of intact membrane. This false positive result also indicated that AFP test sensitive enough to detect occult leakage of fluid through micro stretching.

A study was conducted by Shahin ${ }^{12}$ in Egypt. It was a comparative study on three amniotic fluid marker- prolactine, hcg and Alpha-Feto protein for diagnosis of PROM. The result of that study was found almost similar with the present study. It was conducted among 100 pregnant women evaluate to the most effective marker in vaginal fluid for diagnosis of PROM. By using electro chemical immuno assay (ECLIA) method it was found that Alpha-Feto protein was the most effective one. The sensitivity and specificity was $94 \%$ for AFP. The other two markers had lower sensitivity and specificity. It was $70 \%$ and $76 \%$ for prolactine, $72 \%$ and $84 \%$ for hcg. They highlighted in their study that AFP in vaginal fluid is a accurate diagnostic marker of PROM and its validity is more than prolactine and hcg.

Gaucherand et $\mathrm{al}^{7}$ (1994) conducted a proto type study of the present study in France. By using immune enzyme assay 167 female patients were studied for AFP in vaginal fluid. In this study quantitative measurement of AFP was found as a reliable, simple and rapid diagnostic test. The sensitivity and specificity was observed as $94.5 \%$ and $95.4 \%$ respectively. The level of the sensitivity and specificity was almost nearer to the present study which was $98 \%$ and $84.5 \%$ respectively.

In another research work $\mathrm{Li}$ and Chang ${ }^{13}$ also detected high accuracy of vaginal fluid Alpha-Feto protein for diagnosis of PROM. It was a comparative study of vaginal fluid createnine, hcg and AFP for diagnosis of PROM. The sensitivity and accuracy for AFP was $90 \%$ and $95 \%$ respectively. The level of accuracy was consistent to the accuracy evaluated in this present study. The sensitivity specificity of hcg was much lower and was $80 \%, 70 \%, 75 \%$ respectively.

Using Alpha-Feto protein kits in vaginal fluid a research was performed in Hokhaid University of Japan by Kishida et al ${ }^{14}$. They compared AFP test with Nitrazine paper test among 137 patients. AFP kids highlighted a much better efficacy in diagnosis of PROM. The Nitrazine paper test had $62.1 \%$ whereas AFP kits had $98 \%$ accuracy in detecting PROM. The specificity was $58.3 \%$ for Nitrazine paper and $100 \%$ for AFP test.

\section{Conclusion}

The result of present study and its similarity with other international studies, it can be concluded that AFP in vaginal fluid is a highly accurate test for diagnosis of PROM.

\section{References}

1. Datta DC ,2005, the text book obstetrics, 6th edn, New Central Book Agency (P) Ltd. India, pp.317.

2. Parry S, Strauss III JF 1998, 'Premature Rupture ofthe Fetal Membranes ', NEJM, vol. 338, no. 10, pp. 663-669.

3. Arias F 1993, Practical guide to high-risk pregnancy and delivery , 2nd edn, Harcourt Brace and Company Asia Pvt Ltd, USA, pp. 100.

4. Dechemey AH, Lauren N 2007 , Current Obstetrics and Gynaecology Diagnosis \& Treatment, 10th edn, McGrow Hill, New York, Chicago , London, New Delhi, Singapore, pp.279-281.

5. Medina TM, Hill A 2006, 'Preterm Premature Rupture of Membranes: Diagnosis and Management ', Am Fam Physician, vol. 73, pp. 659-666.

6. Toth P, Mcsuaros C, Csaki G 1990, 'Alpha-Feto protein in vaginal fluid .The early diagnosis of Premature rupture of membranes', Acta Paediatr Hung, vol. 30, pp. 399-402.

7. Gaucherand. P, Guibaud S, Rudigoz R.C, wong A 1994, 'Diagnosis of Premature rupture of membranes by identification of Alpha-Feto Protein in vaginal secretions', Acta Obstet Gy necol scand, vol. 73, pp. 456-459.

8. Mathews F, Neil A 2005, 'Antioxidants and preterm prelabour rupture of the membranes', BJOG: an International Journal of Obstetrics and Gy naecology, Vol. 112, pp. 754-758.

9. Ahmed $\mathrm{N}$ 2006, Maternal and fetal outcome in premature rupture membranes, (Dissertation), FCPS , Obstetrics and Gynaecology, BCPS , Bangladesh.

10. Akter S 2006, Maternal and $f$ etal outcome in preterm premature rupture of membrane, (Dessertation), FCPS, Obstetrics and Gynaecology, BCPS, Bangladesh.

11. Tasnim S, 1995, ' Clnical p rofile and outcome of pr ematur e rupture membranes in Dhaka Medical College Hospital-a study of fiftyfiv e cases ', (Dissertation), Dept. Of Obstetrics and Gynaecology , BCPS, Bangladesh.

12. Shahin M, Ras1an H 2007, 'Comparative study of three amniotic fluid markers in Premature rupture membranes: Prolactin, Beta subunit of Human Chorionic Gonadotropin in and Alpha-Feto Protein', Gynecologic and Obstetric investigation, Vol. 63 pp. 195-199.

13. Li HY, chang TS 2000, 'Vaginal fluid createnine, human chorionic gonedotrop in and Alpha-Feto protein levels for detecting premature rupture of membranes', chiMed J (Taipei), vol. 63, pp. 686-690.

14. Kishida T, Hirao A, Matsulra T, Yamada H, Fujimoto S, Sagawa T, 'Diagnosis of Premature rupture of membrane with an improved Alpha-Feto protein monoclonal antibody ki 't, Clin chem, vol. 41 (10), pp. 150-153.

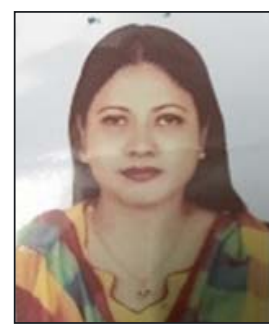

Dr. Nasreen Sultana is a gynaecologist working as a consultant in Rupganj thana Health Complex, she completed MBBS from Sir Salimullah Medical College in 1994. BCS (Health) 1997. She achieved MPH in public health from NIPSOM in 2000 and MS (Gynae and Obs) in 2008.

She also published many articles in different national and international journals. 